\title{
Pristimerin effectively inhibits the malignant phenotypes of uveal melanoma cells by targeting NF-кB pathway
}

\author{
BIAO ZHANG ${ }^{1}$, JING ZHANG ${ }^{1}$ and JINGXUAN PAN ${ }^{1,2}$ \\ ${ }^{1}$ Institute of Tumor Pharmacology, College of Pharmacy, Jinan University; ${ }^{2}$ State Key Laboratory of Ophthalmology, \\ Zhongshan Ophthalmic Center, Sun Yat-Sen University, Guangzhou, Guangdong 510060, P.R. China
}

Received February 5, 2017; Accepted July 13, 2017

DOI: $10.3892 /$ ijo.2017.4079

\begin{abstract}
Uveal melanoma (UM) is a highly aggressive intraocular malignancy that lacks any effective targeted-therapy. Neither survival nor prognosis has been improved for the past decades in patients with metastatic UM. NF- $\mathrm{BB}$ pathway is reported to be abnormally activated in UM. However, the role of $\mathrm{NF}-\kappa \mathrm{B}$ pathway as a potential therapeutical target in UM remains unclear. Here, the effect of pristimerin, a potent inhibitor of NF- $\mathrm{BB}$ pathway, on UM cells in terms of growth, apoptosis, motility, invasion and cancer stem-like cells (CSCs) was evaluated in vitro. We showed that pristimerin suppressed tumor necrosis factor $\alpha(\mathrm{TNF} \alpha)$-induced I $\mathrm{B} \alpha$ phosphorylation, translocation of $\mathrm{p} 65$, and expression of $\mathrm{NF}-\kappa \mathrm{B}$-dependent genes. Moreover, pristimerin decreased cell viability and clonogenic ability of UM cells. A synergistic effect was observed in the treatment of pristimerin combined with vinblastine, a frontline therapeutic agent, in UM. Pristimerin led to a significant increase in the Annexin $\mathrm{V}^{+}$cell population as measured by flow cytometry. We also observed that pristimerin impaired the abilities of migration and invasion in UM cells. Furthermore, pristimerin eliminated the $\mathrm{ALDH}^{+}$ cells and weakened serial re-plating ability of melanosphere. Collectively, pristimerin shows remarkable anticancer activities in UM cells through inactivating NF- $\mathrm{B}$ pathway, revealing that pristimerin may be a promising therapeutic agent in UM.
\end{abstract}

\section{Introduction}

Uveal melanoma (UM), originated from melanocyte malignant transformation, is the most common intraocular tumor in adults (1). The yearly incidence is 5-6 cases per million, and the median age at diagnosis is 62 years (2). Hepatic metastasis is the leading cause of death in UM patients, and the average

Correspondence to: Dr Jingxuan Pan, State Key Laboratory of Ophthalmology, Zhongshan Ophthalmic Center, Sun Yat-Sen University, 54 South Xianlie Road, Guangzhou, Guangdong 510060, P.R. China

E-mail: panjx2@mail.sysu.edu.cn

Key words: pristimerin, NF-кB, uveal melanoma, targeted therapy, apoptosis, migration, invasion, cancer stem-like cells survival time for patients diagnosed with liver metastasis is only 2-14 months (2). Although there are multiple options available for the treatment of primary UM patients, such as surgical resection of diseased eye ball, plaque radiotherapy, transpupillary thermotherapy and chemotherapy (2-4), the 5 -year survival rate displayed no improvement in past decades, which is attributed to lacking effective therapy for metastasis (2). Therefore, there is an urgent demand to develop more efficient agents against both primary and metastatic UM.

Aberrant activation of $\mathrm{NF}-\kappa \mathrm{B}$ is widely present in diverse malignancies (5-9). NF- $\kappa \mathrm{B}$ pathway regulates the transcription of numerous genes which are involved in diverse cellular functions, including apoptosis, proliferation, angiogenesis, immune response, cell invasion, and cancer stem-like cells (CSCs) (10). More importantly, NF- $\mathrm{B}$ pathway may be a potential molecular target for cancer therapy (11). Previous evidence indicates that constitutive activation of NF- $\mathrm{BB}$ can increase UM cellular proliferation and evasion of apoptosis, and is involved in both primary and metastatic UM (12). Thus, pharmacological inhibition of NF- $\kappa$ B may be an effective approach to kill UM cells.

Previous studies demonstrated that pristimerin, a natural product isolated from natural herb plants, is a potent inhibitor of NF- $\kappa$ B pathway $(9,13,14)$ and displays antimicrobial, antiinflammatory, anti-peroxidation activities (13) and anticancer effects in various human malignancies (15-18). Moreover, pristimerin has shown inhibitory effects on proliferation, survival, angiogenesis, metastasis, and CSCs characteristics $(16,17,19-22)$. Thus, we wondered whether this compound also had anticancer activity in UM.

In the present study, we showed the inhibitory activity of pristimerin against $\mathrm{TNF} \alpha$-induced $\mathrm{NF}-\kappa \mathrm{B}$ activation in UM cells. We also found that the downregulation of survivin on mRNA level was critical in pristimerin-inducing apoptosis in UM cells. In addition, pristimerin attenuated the properties of CSCs and the combination of pristimerin and vinblastine, a frontline therapeutic agent, showed a synergistic effect against UM cells. This study suggests that pristimerin is a promising compound for UM treatment.

\section{Materials and methods}

Reagents and antibodies. Pristimerin (Fig. 1A, purity $>99 \%$, HPLC) was purchased from Paypaytech Inc. (Shenzhen, China), and dissolved in dimethyl sulphoxide (DMSO, 
Sigma-Aldrich, Shanghai, China) at a stock concentration of $20 \mathrm{mM}$, and stored at $-20^{\circ} \mathrm{C}$. Vinblastine was obtained from Selleck (Shanghai, China). Antibodies against survivin, Bcl- $\mathrm{X}_{\mathrm{L}}$ and PCNA were from Santa Cruz Biotech (Santa Cruz,

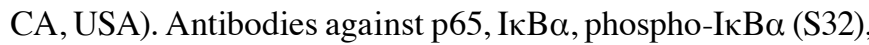
Tubulin, matrix metalloproteinase 2 (MMP2), matrix metalloproteinase 9 (MMP9), Slug, Sox2, Nanog and KLF4 were purchased from Cell Signaling Technology (Beverly, MA, USA). Antibodies against PARP (clone 4C10-5), caspase-3, active caspase-3 (CM1), cytochrome $c$ (clone 6H2.B4), $\mathrm{X}$-linked inhibitor of apoptosis protein (XIAP), Bcl-2, and c-Myc were purchased from BD Biosciences (San Jose, CA, USA). Anti-mouse and anti-rabbit immunoglobulin $\mathrm{G}$ fluorescent-conjugated secondary antibodies were purchased from LI-COR Biotechnology (NE, USA). Dual-luciferase assay kit was provided by Promega (Madison, WI, USA). The Aldeflour kit was from StemCell Technologies (Vancouver, Canada). Gelatin (G1890-100G) was obtained from Sigma-Aldrich). Coomassie Brilliant Blue R-250 (44329-7C) was from Farco Chemical Supplies (Hong Kong, China).

Cell culture. The UM cells 92.1, Mel 270, Omm 1 and Omm 2.3 were cultured in RPMI-1640 supplemented with $10 \%$ fetal bovine serum (FBS), penicillin $(100 \mathrm{U} / \mathrm{ml})$, streptomycin $(100 \mu \mathrm{g} / \mathrm{ml})$ and L-glutamine $(2 \mathrm{mM})$, and incubated at $37^{\circ} \mathrm{C}$ and $5 \% \mathrm{CO}_{2}$, as described previously (23). 293T cells were cultured in DMEM supplemented with $10 \%$ FBS, penicillin $(100 \mathrm{U} / \mathrm{ml})$, streptomycin $(100 \mu \mathrm{g} / \mathrm{ml})$ and incubated at $37^{\circ} \mathrm{C}$ and $5 \% \mathrm{CO}_{2}$.

Dual luciferase reporter assay. Omm 1, 92.1 and Omm 2.3 cells seeded in 24-well plates were co-transfected with $N F-\kappa B-T A T A-L u c$ reporter plasmid $(0.5 \mu \mathrm{g})$ and Renilla luciferase reporter plasmid (10 ng), respectively. After $24 \mathrm{~h}$, these UM cells were exposed to the indicated concentrations of pristimerin for $16 \mathrm{~h}$, then added with TNF $\alpha(10 \mathrm{ng} / \mathrm{ml})$ for $8 \mathrm{~h}$ and measured with dual-luciferase assay kit as described previously $(9,24)$. The luciferase activities were normalized with NF-кB-dependent firefly luciferase to Renilla luciferase activity.

Western blot analysis. The prepared cell lysates were quantified by Pierce ${ }^{\mathrm{TM}}$ BCA Protein assay kit (Thermo Scientific, USA) according to the manufacturer's instructions. Protein samples were subjected to SDS-PAGE and then blotted to nitrocellulose membranes. After blocked by $5 \%$ skim milk, membranes were subsequently incubated with the primary antibodies overnight at $4^{\circ} \mathrm{C}$ before incubation with appropriate secondary antibodies. The immunoblots were recorded with the Odyssey infrared imaging system (LI-COR).

Immunofluorescence staining. After cultured overnight, 92.1 and Omm 1 cells were incubated with or without pristimerin for $24 \mathrm{~h}$, and then the cells were stimulated with TNFa (20 ng/ml) for $15 \mathrm{~min}$ before fixed by $4 \%$ paraformaldehyde. After permeabilization by $0.2 \%$ (v/v) Triton X-100 at room temperature for $15 \mathrm{~min}$, the samples were washed with $500 \mu \mathrm{l}$ of PBS for 5 min three times. Subsequently, PBS buffer containing $5 \%$ bovine serum albumin was used to block non-specifical binding for $1 \mathrm{~h}$ and then the cells were incu- bated with $200 \mu \mathrm{l}$ of PBS containing the primary antibody for $1 \mathrm{~h}$ at room temperature. After washing with PBS containing $0.1 \%$ (v/v) NP-40, the cells were incubated with $200 \mu \mathrm{l}$ of PBS containing the secondary antibody for $1 \mathrm{~h}$ at room temperature. Nuclear staining was performed with DAPI for $20 \mathrm{~min}$. After washing with PBS for $5 \mathrm{~min}$, all samples were added with a half drop of anti-fade regent and then sealed by nail polish (9).

Preparation of cytoplasmic and nuclear fractionations. After stimulation with TNF $\alpha(10 \mathrm{ng} / \mathrm{ml})$, cells treated with or without pristimerin were collected by centrifugation and washed with PBS. Pellets resuspended in $150 \mu \mathrm{l}$ cold lysis buffer $(10 \mathrm{mM}$ HEPES, $10 \mathrm{mM} \mathrm{KCl,} 0.1 \mathrm{mM}$ EDTA, 0.4\% NP-40, $1 \mathrm{mM}$ DTT, $0.5 \mathrm{mM}$ PMSF, $1 \mathrm{mM}$ sodium orthovanadate and Complete Protease Inhibitor Mix) by pipetting up and down $\sim 10$ times were incubated on ice for $10 \mathrm{~min}$, the lysates were centrifuged at $20,000 \mathrm{~g}(9,25)$. The supernatants were transferred to a fresh tube as cytoplasmic extracts. After rinsed with the lysis buffer, the pellets were vigorously suspended in nuclear protein extraction buffer (20 mM HEPES, $0.4 \mathrm{mM}$ $\mathrm{NaCl}, 1 \mathrm{mM}$ EDTA, $1 \mathrm{mM}$ DTT, $0.5 \mathrm{mM}$ phenylmethylsulfonyl fluoride (PMSF), $1 \mathrm{mM}$ sodium orthovanadate and Complete Protease Inhibitor Mix) and incubated for $15 \mathrm{~min}$. After centrifugation with $10 \mathrm{~min}$ at $20,000 \mathrm{~g}$, the supernatant was referred to as nuclear fractions $(9,25)$.

Preparation of whole cell lysates and cytosolic fractionations. Control or treated cells were pelleted by centrifugation and then rinsed with PBS. The whole cell lysates were prepared with RIPA buffer (1X PBS, $0.1 \%$ SDS, $1 \%$ NP-40, $0.5 \%$ sodium deoxycholate) supplemented with $1 \mathrm{X}$ protease inhibitor cocktail, $10 \mathrm{mM} \beta$-glycerophosphate, $1 \mathrm{mM}$ sodium orthovanadate, $10 \mathrm{mM}$ sodium fluoride, and $1 \mathrm{mM}$ PMSF (26). The cytosolic fraction was extracted with digitonin extraction buffer $(10 \mathrm{mM}$ PIPES, 0.015\% digitonin, $300 \mathrm{mM}$ sucrose, $100 \mathrm{mM} \mathrm{NaCl}$, $3 \mathrm{mM} \mathrm{MgCl}_{2}, 5 \mathrm{mM}$ EDTA, and $1 \mathrm{mM}$ PMSF) on ice for $10 \mathrm{~min}$ and then centrifuged at $20,000 \mathrm{~g}$ for $10 \mathrm{~min}$ at $4^{\circ} \mathrm{C}$. The supernatants were collected as cytosolic fractions (27).

Cell viability assay. The UM cells (5,000 cells/well) seeded into 96-well plates overnight were then exposed to serially diluted pristimerin for $72 \mathrm{~h}$. Optical intensity was measured by microplate reader after addition with $20 \mu \mathrm{l}$ mixture of MTS and PMS (28).

Colony formation assay. The UM cells were treated with various concentrations of pristimerin for $24 \mathrm{~h}$ and rinsed with PBS, then 8,000 cells were seeded to a modified drug-free double layer soft agar system (29). After 10-14 days, the number of colonies composed of $>50$ cells was counted under a microscope.

Cell cycle analysis by flow cytometry. After pretreated with or without pristimerin for $24 \mathrm{~h}$ and washed with PBS, UM cells were fixed with $66 \%$ ethanol overnight. Cells rinsed with PBS were pelleted by centrifugation. Subsequently, the pellets were resuspended in PBS and stained with propidium iodide (PI, $50 \mu \mathrm{g} / \mathrm{ml})$ and RNase $(2.5 \mu \mathrm{g} / \mathrm{ml})$ for $30 \mathrm{~min}$ at room temperature. DNA content was analyzed by flow cytometry (9). 
Apoptosis analysis by flow cytometry. Annexin V-FITC/PI double staining was used to detect apoptosis by flow cytometry. Cells pre-incubated with or without pristimerin were collected by centrifugation and washed with PBS, and then stained with $0.3 \%$ Annexin V-FITC in binding buffer for $15 \mathrm{~min}$ at room temperature in the dark. After centrifuged at $250 \mathrm{~g}$ and resuspended in $1 \mathrm{X}$ binding buffer, the cells were added with PI before flow cytometry analysis $(9,29)$.

Measurement of mitochondrial transmembrane potential. UM cells were incubated with $2.0 \mu \mathrm{M}$ pristimerin for different durations, and then stained with MitoTracker probes (CMXRos and MTGreen) for $1 \mathrm{~h}$ at $37^{\circ} \mathrm{C}$. After being centrifuged at $250 \mathrm{~g}$ for $10 \mathrm{~min}$, the pellets were raised in PBS and subjected to flow cytometry to detect the changes in mitochondrial transmembrane potential $(\Delta \psi)(25,29)$.

Lentiviral transfection. Lentiviruses were produced by transient transfection in 293T cells with control shRNA (Scramble) or specific shRNA together with the pCMV-dR8.2 packing construct and the pCMV-VSVG envelope construct. 92.1 and Omm 1 cells $\left(1 \times 10^{5}\right.$ cells/well) were infected twice with viruscontaining supernatants. The cells were then incubated in the presence of puromycin $(1 \mu \mathrm{g} / \mathrm{ml})$ for $\sim 5$ days. Scramble and specific shRNAs were purchased from Sigma-Aldrich, and the sequences were as follows: PLKO.1-Non-target shRNA: CCG GGC GCG ATA GCG CTA ATA ATT TCT CGA GAA ATT ATT AGC GCT ATC GCG CTT TTT; shsurvivin: CCG GGA AGA ATT AAC CCT TGG TGA ACT CGA GTT CAC CAA GGG TTA ATT CTT CTT TTTG. The Omm 1 cells overexpressed survivin were established with the same methods. Constructs bearing full length human survivin cDNA in pTSB-CMV-MCS-SBP-tRFP-F2A-PuroR and empty vector were provided by Transheep (Shanghai, China). Human baculoviral inhibitor of apoptosis repeat-containing 5 (BIRC5, NCBI Reference Sequence ID: NG_029069.1) was cloned into the pTSB-CMV-MCS-SBP-tRFP-F2A-PuroR (lentivirus) plasmid using ClonExpress MultiS One Step Cloning kit, which was provided by Vazyme (Nanjing, China) and clone sites were EcoRI and BamHI. The efficiency of knockdown or overexpression was examined by western blot analysis.

Real-time quantitative PCR. After pre-incubated with various concentrations of pristimerin, total RNA was extracted by TRIzol reagent, and then reverse-transcribed into first-strand complementary DNA with maxima first strand cDNA synthesis kit. GAPDH was used as an endogenous reference. The PCR primers were as follows: survivin forward, 5'-CAT CTC TAC ATT CAA GAA CTG G-3'; reverse, 5'-GGT TAA TTC TTC AAA CTG CTT C-3' (30). GAPDH forward, 5'-GAT CGA ATT AAA CCT TAT CGT CGT-3'; reverse, 5'-AGC AGC AGA ACT TCC ACT CGG T-3'.

The qRT-PCR reaction was performed in SYBR Premix EX Taq with Bio-Rad CFX96 Real-Time Thermocycler according to the manufacturer's instructions $(26,29)$. In relative quantification, $\Delta \Delta \mathrm{Cq}$ method was used, as described previously (31).

The scratch wound healing assay. 92.1 and Omm 1 cells $\left(5 \times 10^{5} /\right.$ well) were cultured in a 6 -well plate supplemented with
$10 \%$ FBS. The monolayer was gently and slowly scratched with a $200-\mu 1$ pipette tip across the center of the well at $\sim 90 \%$ confluence. The cells were treated with or without pristimerin $(0.25$ or $0.5 \mu \mathrm{M})$, the same wounded area was recorded under a microscope at different time periods $(29,32)$.

Migration and invasion assay. After exposed to vehicle, 0.25 or $0.5 \mu \mathrm{M}$ pristimerin for $24 \mathrm{~h}$, equal amounts of 92.1 and Omm 1 cells were cultured in the upper of Transwell chamber covered with or without Matrigel and contained with FBS-free medium, while to the lower chamber $20 \%$ FBS was added as chemoattractant. After $48 \mathrm{~h}$, the cells on the surface of chamber were removed by a cotton swab, and the migrated or invaded cells were fixed with $4 \%$ paraformaldehyde and stained by crystal violet. The cells in three randomly selected low power fields were counted (29).

Gelatin zymography assay. 92.1 and Omm 1 cells were seeded into 6-well culture plates. When cells grew to $\sim 80 \%$ confluency, were washed by serum-free medium three times. Cells were incubated with serum-free medium with or without pristimerin $(0.25$ and $0.5 \mu \mathrm{M})$ for $24 \mathrm{~h}$. MDA-MB-231 cells were used as positive control (33). Serum-free medium without cells was used as negative control. After incubation, the supernatants were collected and were subjected to SDS-PAGE using $10 \%$ acrylamide gels containing $0.1 \%$ gelatin. After electrophoresis, the gels were washed for $15 \mathrm{~min}$ at room temperature in a buffer $\left(50 \mathrm{mM}\right.$ Tris- $\mathrm{Cl} \mathrm{pH} 7.6,10 \mathrm{mM} \mathrm{CaCl}_{2}$, $20 \mathrm{mM} \mathrm{NaCl}, 1 \mu \mathrm{M} \mathrm{ZnCl}_{2}$ and $2.5 \%$ Triton $\left.\mathrm{X}-100\right)$ three times. After incubation with activation buffer $(50 \mathrm{mM}$ Tris- $\mathrm{Cl}$ $\mathrm{pH} 7.6,10 \mathrm{mM} \mathrm{CaCl}{ }_{2}, 20 \mathrm{mM} \mathrm{NaCl}, 1 \mu \mathrm{M} \mathrm{ZnCl}_{2}$ ) for $48 \mathrm{~h}$ at $37^{\circ} \mathrm{C}$, gels were stained with $0.25 \%$ Coomassie Brilliant Blue R-250 in $40 \%$ methanol and $10 \%$ acetic acid and then briefly destained in $10 \%$ acetic acid and $30 \%$ methanol. The locations of gelatinolytic enzymes were visualized as clear bands on the background (34). The experiment was repeated three times and the optical density of each bands was quantitated by image pro plus.

Aldehyde dehydrogenase (ALDH) assay. The Aldefluor kit was used to identify a population of cells with high ALDH enzymatic activity (35). In brief, UM cells (92.1 and Omm 1) pre-incubated with DMSO or $1.0 \mu \mathrm{M}$ pristimerin for $24 \mathrm{~h}$, and then incubated with $5 \mu \mathrm{l}$ ALDH reagent in the absence or presence of $5 \mu \mathrm{lDEAB}$ for $1 \mathrm{~h}$ at $37^{\circ} \mathrm{C}$. After washed with ALDH assay buffer, the cells were resuspended in ALDH assay buffer. The proportion of $\mathrm{ALDH}^{+}$cells was defined by flow cytometry $(29,35)$.

Melanosphere culture. 92.1 and Omm 1 cells pretreated with DMSO or $1.0 \mu \mathrm{M}$ pristimerin for $24 \mathrm{~h}$ were seeded to 24 -well low attachment plates containing $500 \mu \mathrm{l}$ DMEM/F12 medium supplemented with $1 \mathrm{X} \mathrm{B27,} 10 \mathrm{ng} / \mathrm{ml}$ basic fibroblast growth factor (bFGF), $20 \mathrm{ng} / \mathrm{ml}$ epidermal growth factor (EGF) each well. After $\sim 14$ days, melanospheres with $>50$ cells were counted as per the universal standard $(29,36)$. The secondary and tertiary rounds of melanosphere cultures were implemented in drug-free culture after collecting the first or second round of tumor sphere culture cells. Representative images were taken by a microscope. 
A

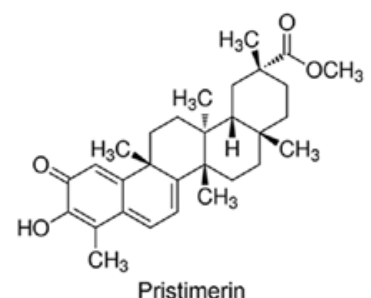

B
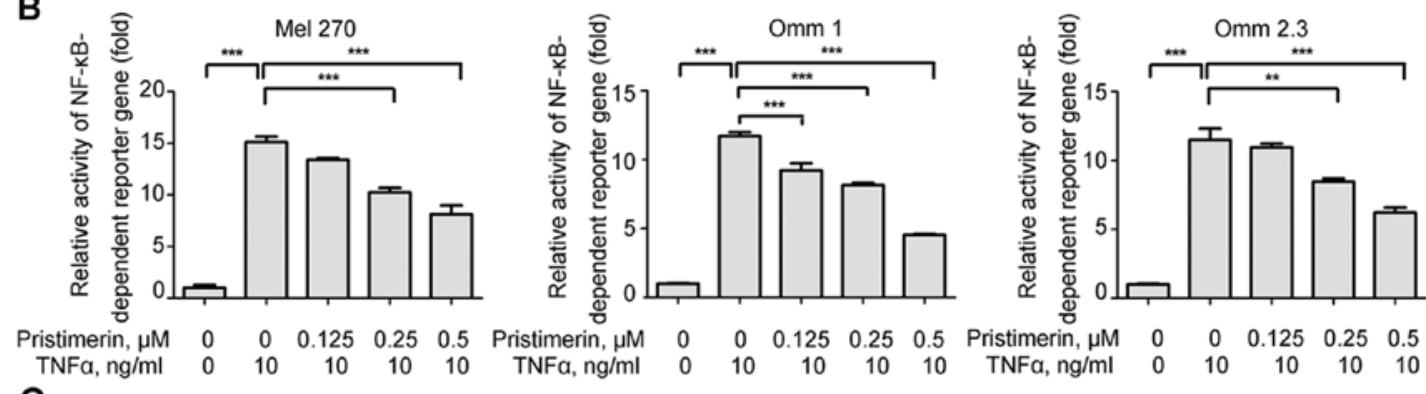

C
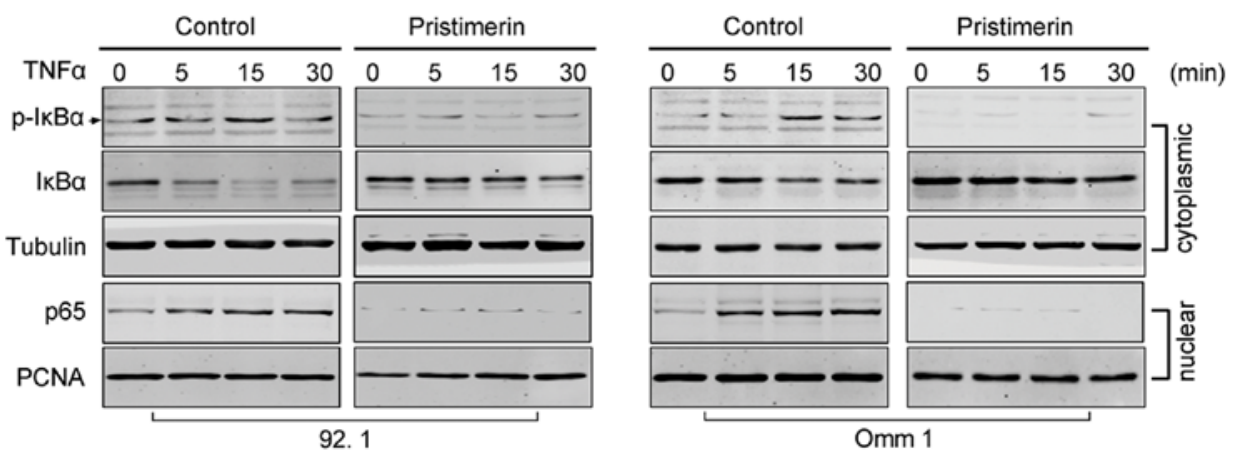

D
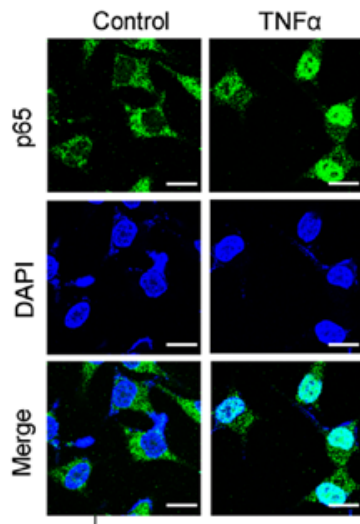

Pristimerin
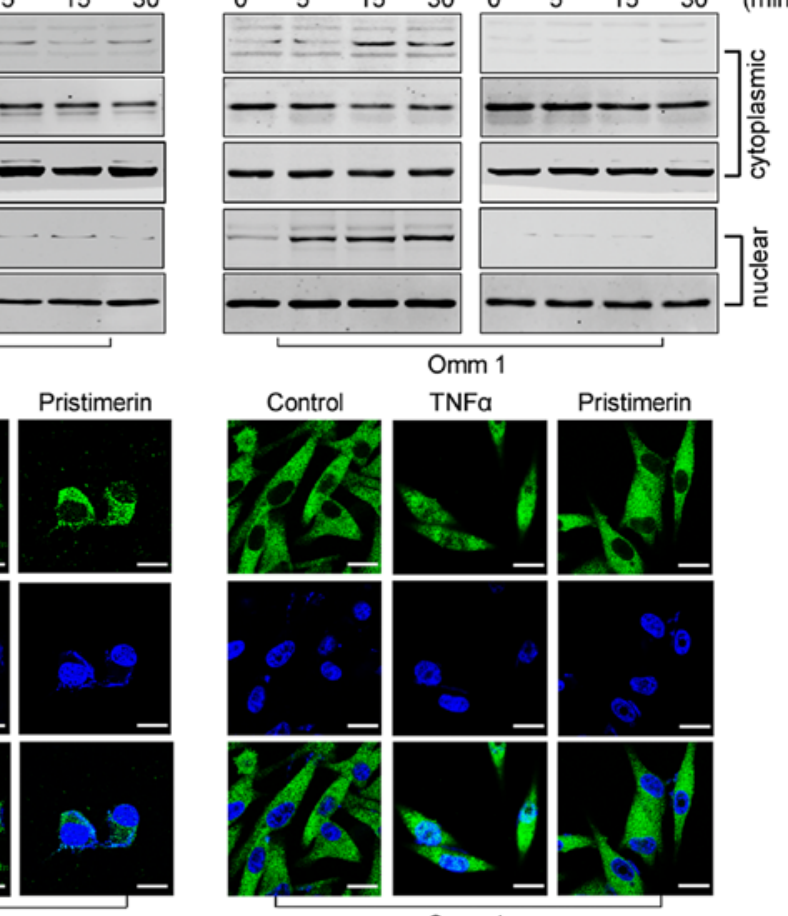

Pristimerin

92. 1

Omm 1

E

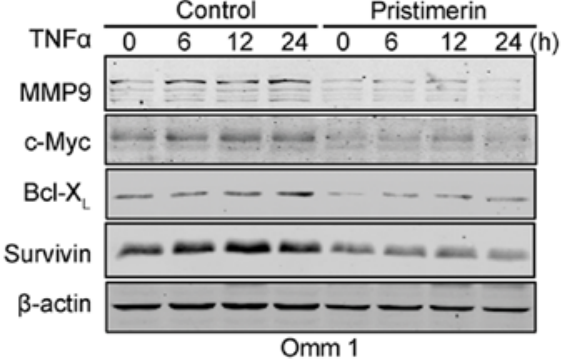

Figure 1. Pristimerin suppresses TNF $\alpha$-induced NF-kB activation in uveal melanoma cells. (A) The structure of pristimerin is shown. (B) Pristimerin inhibited TNFo-induced NF-kB-dependent reporter gene expression in UM cells. Mel 270, Omm 1 and Omm 2.3 cells co-transfected with $N F-\kappa B$-TATA-Luc reporter plasmid and Renilla luciferase reporter plasmid were treated with various concentrations of pristimerin for $16 \mathrm{~h}$, and then stimulated with TNF $\alpha$ for $8 \mathrm{~h}$; the luciferase activity of cells was detected. The levels of firefly luciferase activity were normalized to Renilla luciferase activity. The results represented the means \pm SE of three independent experiments. ${ }^{* *} \mathrm{P}<0.01,{ }^{* * *} \mathrm{P}<0.001$, one-way ANOVA, post hoc intergroup comparisons, Tukey's test. (C and D) Pristimerin blocked the nuclear translocation of $\mathrm{p} 65$ in UM cells stimulated by TNF $\alpha .92 .1$ or Omm 1 cells were pretreated with or without $1.0 \mu \mathrm{M}$ pristimerin for $12 \mathrm{~h}$, then stimulated with TNFa $(10 \mathrm{ng} / \mathrm{ml})$ at the indicated time; cytosolic and nucleus fractionations were subjected to western blot analysis. Tubulin was a cytoplasmic loading control, while PCNA was a nuclear loading control (C). 92.1 and Omm 1 cells were pretreated with medium containing DMSO or $0.5 \mu \mathrm{M}$ pristimerin for $24 \mathrm{~h}$, and then incubated with TNF $\alpha(10 \mathrm{ng} / \mathrm{ml})$ for $15 \mathrm{~min}$, undergoing immunofluorescence analysis of p65. DAPI was used to stain the nuclear (D). Scale bar represents $20 \mu \mathrm{m}$. (E) Pristimerin decreased the levels of NF-kB-dependent prosurvival proteins in UM cells. After pre-incubation with pristimerin for $12 \mathrm{~h}, \mathrm{Omm} 1$ cells were exposed to $0.1 \mathrm{nM} \mathrm{TNF} \alpha$ for the indicated durations, and then western blot analysis was performed. 

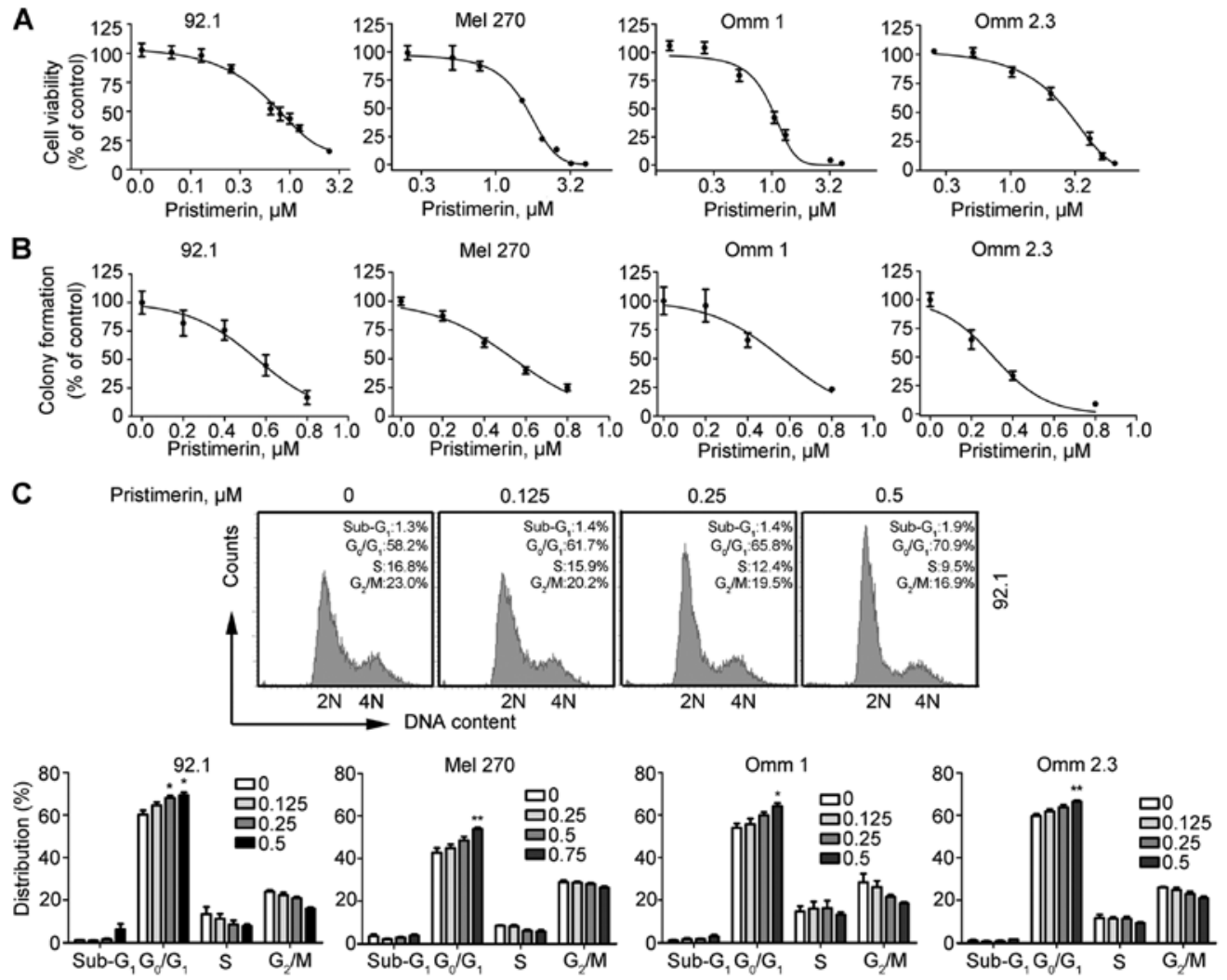

Figure 2. Pristimerin inhibits the growth of UM cells. (A) Pristimerin decreased the cell viability of UM cells. The indicated UM cells were treated with escalating concentrations of pristimerin for $72 \mathrm{~h}$, and then the MTS assay was employed to detect the cell viability. (B) Pristimerin suppressed the clonogenicity of UM cells. After treated with pristimerin, UM cells were seeded to double layer soft agar culture system. Colonies were counted after 10-14 days and normalized to the control. (C) Pristimerin elicited $\mathrm{G}_{1}$-phase arrest in UM cells. UM cells were exposed to diverse concentrations of pristimerin for $24 \mathrm{~h}$, and subsequently stained with PI. Cell cycle analysis was conducted by flow cytometry. The results represent the means \pm SE of three independent experiments. ${ }^{*} \mathrm{P}<0.05,{ }^{* *} \mathrm{P}<0.01$, One-way ANOVA, post hoc intergroup comparisons, Tukey's test.

Statistical analysis. All experiments were performed at least thrice, and the results are expressed as the means \pm standard error (SE), unless otherwise stated. GraphPad Prism 5.0 software was used for statistical analysis. Comparison between 2 groups used two-tailed Student's t-test, and comparison among multiple groups involved one-way ANOVA with post hoc intergroup comparisons using Tukey's test. $\mathrm{P}<0.05$ was regarded as statistically significant.

\section{Results}

Pristimerin blocks $T N F \alpha$-induced $N F-\kappa B$ activation in $U M$ cells. Our previous report indicated that pristimerin potently inhibits activation of canonical $\mathrm{NF}-\kappa \mathrm{B}$ pathway in leukemia cells (9). Here, we tested the effect of pristimerin in UM cells. We first examined whether pristimerin exerted the inhibitory effect on $\mathrm{TNF} \alpha$-induced $\mathrm{NF}-\kappa \mathrm{B}$-dependent reporter gene transcription. The results showed that the NF- $\kappa \mathrm{B}$ dependent luciferase activity was increased after $\mathrm{TNF} \alpha$ stimulation in UM cells. This effect was inhibited by pristimerin in a dose-dependent manner (Fig. 1B). Because the ubiquitinationdependent degradation of $\mathrm{I} \kappa \mathrm{B} \alpha$ protein triggers p65 nuclear translocation, which is a critical step in the activation of the canonical NF- $\kappa \mathrm{B}$ pathway (37), we determined the influence of pristimerin on $\mathrm{I} \kappa \mathrm{B} \alpha$ and $\mathrm{p} 65$. Western blot analysis of cytoplasmic fractionations showed that the levels of phosphorylated $\mathrm{I} \kappa \mathrm{B} \alpha$ in the cytoplasm were appreciably increased after TNF $\alpha$ induction compared to the untreated control, while the total $\mathrm{I} \kappa \mathrm{B} \alpha$ was coincidently decreased (Fig. 1C). However, the phosphorylation of $\mathrm{I} \kappa \mathrm{B} \alpha$ was blocked, and the level of total $\mathrm{I} \kappa \mathrm{B} \alpha$ remained constant in the cells that were pretreated with pristimerin (Fig. 1C). Consistently, the level of p65 in nuclear fractionation was remarkably escalated after TNF $\alpha$ stimulation (Fig. 1C), which was diminished by the presence of pristimerin (Fig. 1C). On the other hand, immunofluorescence staining analysis similarly revealed that nuclear translocation of p65 was prominently increased after TNF $\alpha$ stimulation; whereas pristimerin abrogated its translocation in both 92.1 and Omm 1 cells (Fig. 1D).

We next ascertained the effect of pristimerin on the expression of encoding products of NF- $\kappa \mathrm{B}$-dependent genes involved in cell survival by western blotting (10). The expression of MMP9, c-Myc, Bcl- $\mathrm{X}_{\mathrm{L}}$ and survivin was increased after stimulation with TNF $\alpha$ (Fig. 1E). Nevertheless, pristimerin blocked such an increase (Fig. 1E).

Taken together, our results suggested that pristimerin represses the activation of the canonical NF- $\kappa \mathrm{B}$ pathway.

Pristimerin suppresses the growth of UM cells. Seventytwo-hour cell-based MTS assay revealed that pristimerin significantly inhibited the cell viability of 92.1, Mel 270, Omm 1 and $\mathrm{Omm} 2.3$ cells, and the $\mathrm{IC}_{50}$ values were 1.1, 1.7, 2.2 and $2.9 \mu \mathrm{M}$, respectively (Fig. 2A). Given the advantages of colony formation assay in reflecting malignant behavior of tumor 
A Pristimerin, $\mu \mathrm{M}$
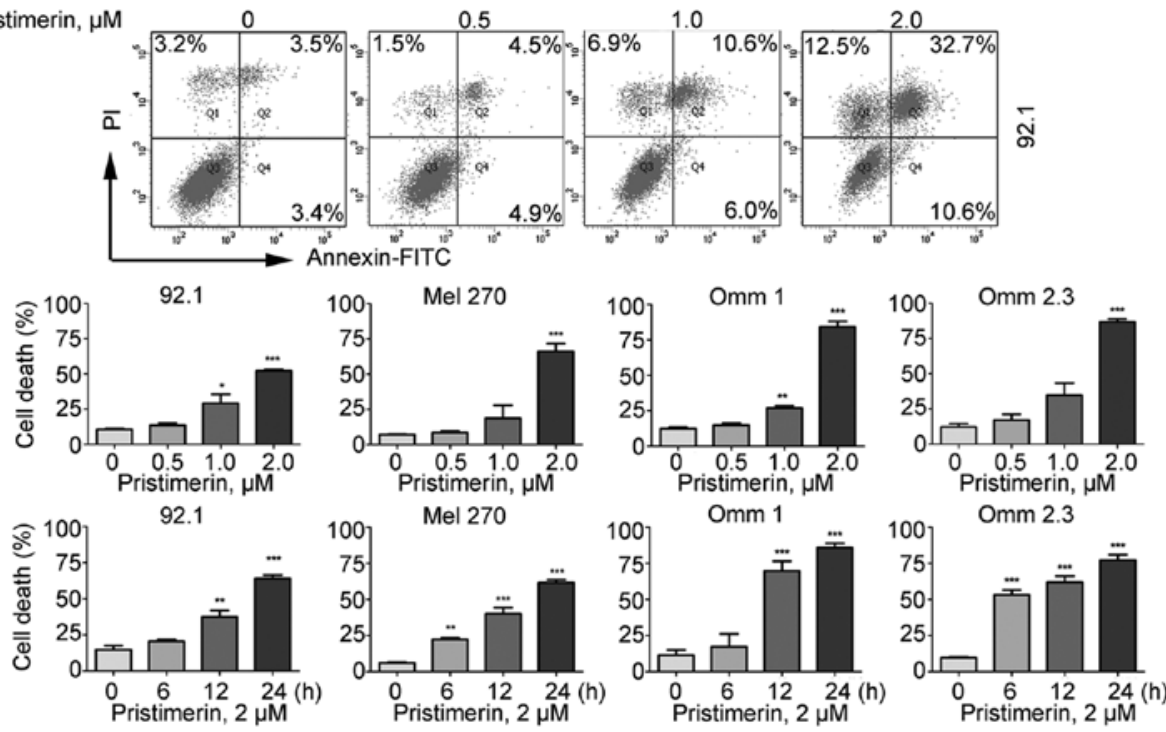

B

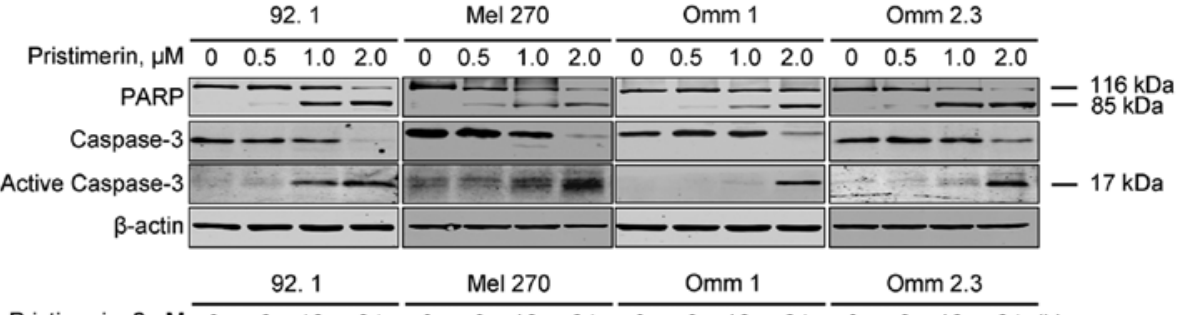

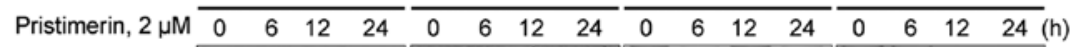
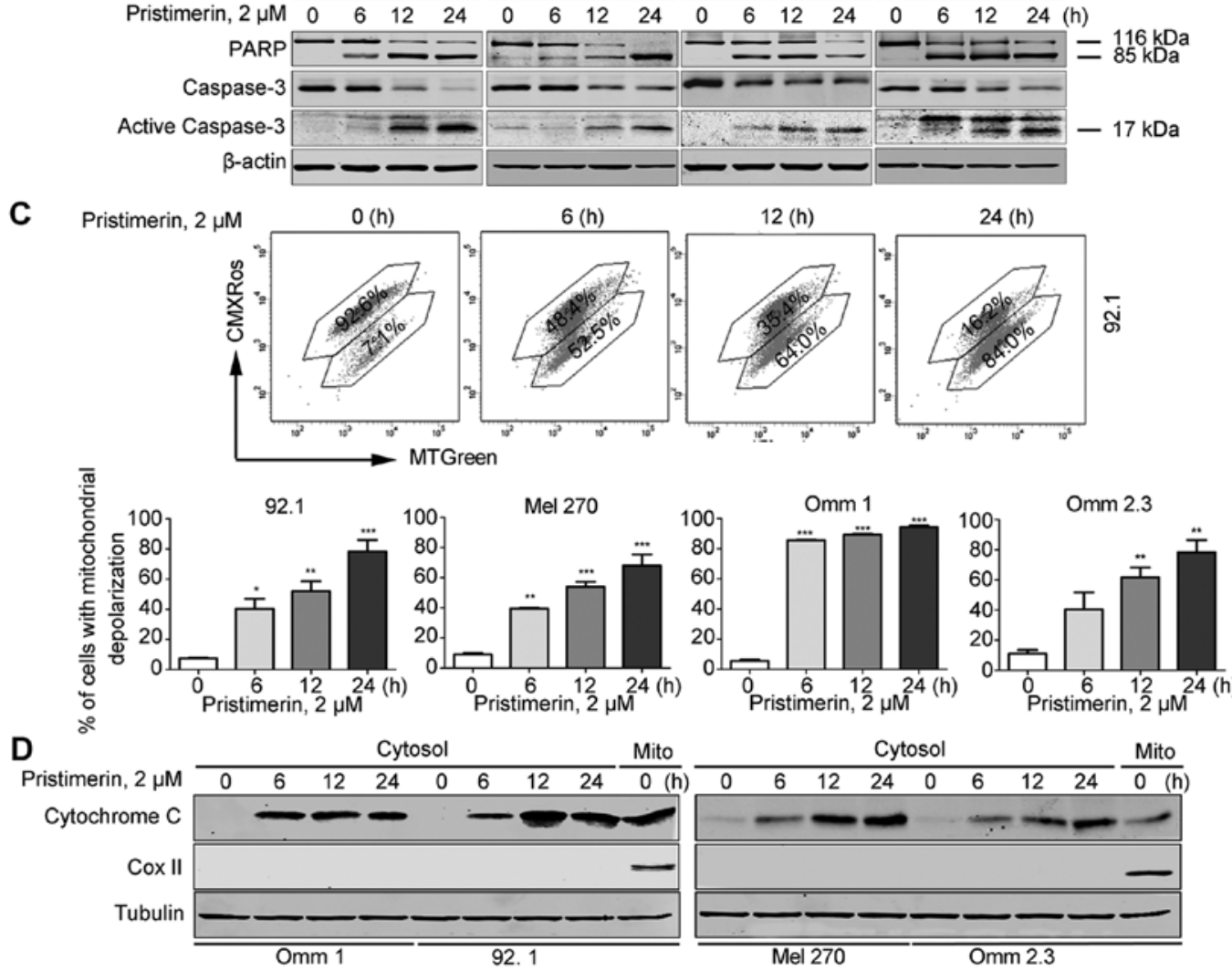

Figure 3. Pristimerin induces intrinsic apoptosis in UM cells. (A-D) UM cells were treated with different concentrations of pristimerin for $24 \mathrm{~h}$, or $2.0 \mu \mathrm{M}$ pristimerin for the indicated times. (A) Pristimerin induced apoptosis of UM cells in a dose- and time-dependent manner. The representative flow cytometry histograms of Annexin V-FITC/PI double staining are shown (top), statistical chart showed the quantitative analysis of three independent experiments (bottom). The results represent the means $\pm \mathrm{SE}$ of three independent experiments. ${ }^{*} \mathrm{P}<0.05,{ }^{* *} \mathrm{P}<0.01,{ }^{* * * *} \mathrm{P}<0.001$, one-way ANOVA, post hoc intergroup comparisons, Tukey's test. (B) Pristimerin decreased the expression of apoptosis-indicative proteins in dose- and time-dependent manner. Western blotting showed the effect of pristimerin on expression of apoptosis-indicative proteins including PARP, caspase-3 and active caspase-3. (C) Pristimerin triggered the mitochondrial depolarization of UM cells. The mitochondrial depolarization of UM cells was detected by flow cytometry after treatment with pristimerin. UM cells pre-incubated with $2.0 \mu \mathrm{M}$ pristimerin in the indicated time periods and then stained with CMXRos and MTGreen. Mitochondrial membrane potential $(\Delta \psi)$ was analyzed by flow cytometry. The results represented the means $\pm \mathrm{SE}$ of three independent experiments. ${ }^{*} \mathrm{P}<0.05,{ }^{* * *} \mathrm{P}<0.01,{ }^{* * *} \mathrm{P}<0.001$, one-way ANOVA, post hoc intergroup comparisons, Tukey's test. (D) Pristimerin induced the release of cytochrome $c$ in UM cells. Western blotting showed the level of cytochrome $c$ in cytoplasm, and tubulin as a loading control for cytosol. 


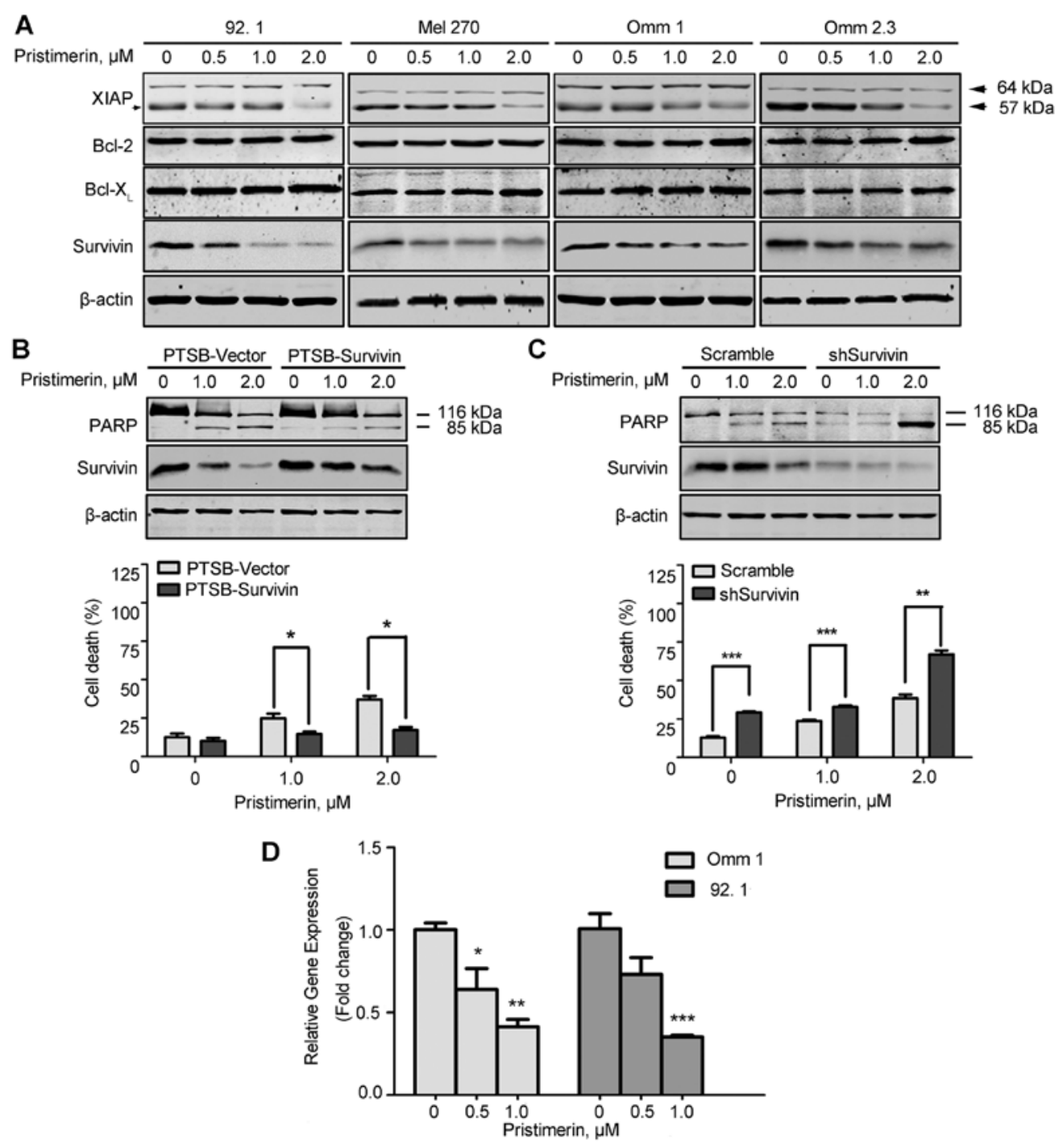

Figure 4. Survivin is critical in pristimerin-induced apoptosis in UM cells. (A) Effect of pristimerin on expression of apoptosis-relative proteins. UM cells were treated with various concentrations of pristimerin for $24 \mathrm{~h}$; the expression of apoptosis related proteins was examined by western blotting. $\beta$-actin was used as a loading control. (B) Omm 1 cells were transiently transfected with constructs encoding full-length human survivin or empty vector (pTSB-CMVMCS-SBP-tRFP-F2A-PuroR) for $24 \mathrm{~h}$, then exposed to pristimerin for another $24 \mathrm{~h}$, and then subjected to western blot analysis (top) and trypan blue exclusion assay (bottom). (C) 92.1 cells were transfected with survivin shRNA or scramble shRNA, then exposed to pristimerin for $24 \mathrm{~h}$, western blot analysis (top) and trypan blue exclusion assay (bottom) were performed. (D) Pristimerin decreased survivin at the level of transcription. The mRNA level of BIRC5 (encoding survivin) after treatment with pristimerin was determined by qRT-PCR in 92.1 and Omm 1 cells. The results represent the means \pm SE of three independent experiments. ${ }^{*} \mathrm{P}<0.05,{ }^{* *} \mathrm{P}<0.01,{ }^{* * *} \mathrm{P}<0.001$, one-way ANOVA, post hoc intergroup comparisons, Tukey's test.

cells, we assessed the impact of pristimerin on anchorageindependent growth of UM cells in soft agar. The results indicated that pristimerin significantly inhibited the formation of colony in a dose-dependent manner (Fig. 2B).

To further study the role of pristimerin in the growth of UM cells, cell cycle distribution analysis was performed after UM cells were exposed to different concentrations of pristimerin for $24 \mathrm{~h}$. The results showed that pristimerin caused $\mathrm{G}_{1}$-phase arrest in UM cells (Fig. 2C).

Pristimerin exerts induction of apoptosis in UM cells. We carried out flow cytometry analysis based on Annexin V-FITC/PI double staining and found that pristimerin remarkably induced cell death in UM cells in a dose- and time-dependent manner (Fig. 3A). Western blot analysis revealed that pristimerin induced cleavage of PARP and caspase-3 in UM cells (Fig. 3B), which demonstrated the occurrence of apoptosis induced by pristimerin.
Next, we evaluated the effect of pristimerin on mitochondrial depolarization in UM cells. After being treated with pristimerin, the cell populations with loss of mitochondrial transmembrane potential were significantly increased (Fig. 3C). In parallel, western blot analysis showed that the levels of cytochrome $c$ in the cytosolic fractionation were increased in a time-dependent manner (Fig. 3D). These results suggested that pristimerin might cause damage of mitochondria and trigger the intrinsic pathway of apoptosis in UM cells.

Survivin plays an important role in pristimerin-induced apoptosis. To dissect the mechanism by which pristimerin induced apoptosis in UM cells, we next measured apoptosisrelated proteins. The results showed that pristimerin decreased the expression of XIAP and survivin, but not Bcl-2 and Bcl-X $\mathrm{L}_{\mathrm{L}}$ (Fig. 4A). Given that survivin was obviously declined 
A
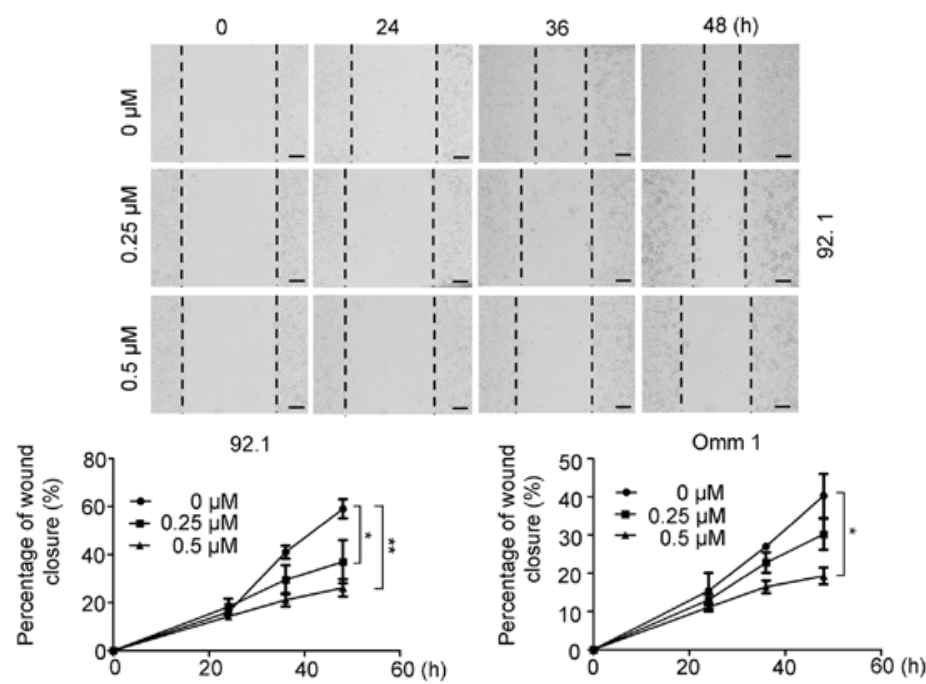

B

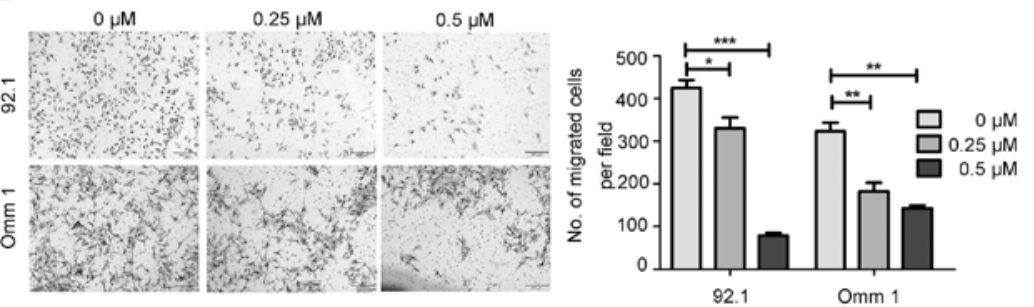

C
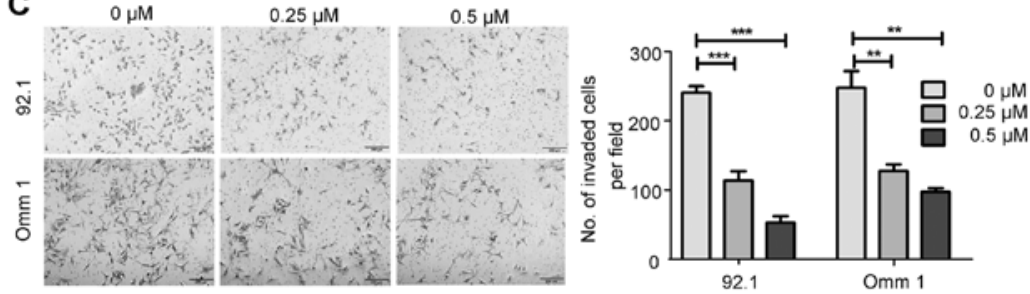

D

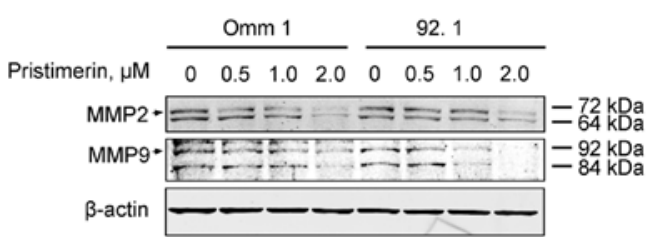

E
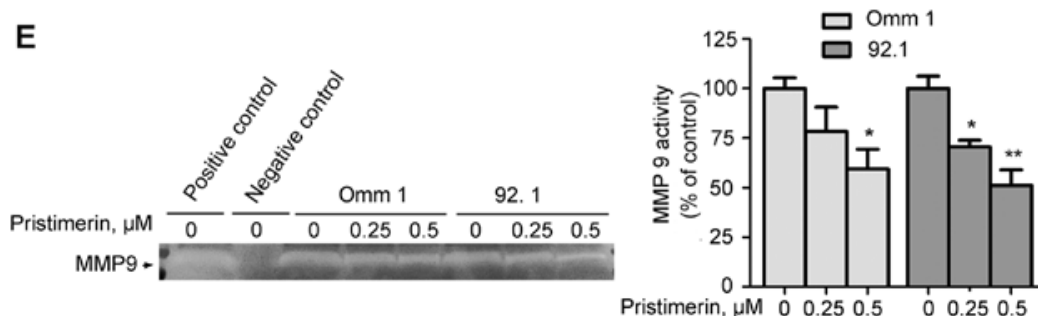

Figure 5. Pristimerin impairs the ability of migration and invasion in UM cells. (A) Pristimerin reduced the motility of UM cells. After 92.1 and Omm 1 cells were seeded in 6-well plates overnight, a wound was made by a 200- $\mu 1$ pipette tip. The cells were exposed to vehicle, 0.25 or $0.5 \mu \mathrm{M}$ pristimerin for the indicated periods, and the wound closure was recorded under microscope. The images were the representative results (top), while the graphs were the quantitative analysis of the percentage of wound closure at different time-points (bottom). Data were shown as the means \pm SE. ${ }^{*} \mathrm{P}<0.05,{ }^{* *} \mathrm{P}<0.01$, one-way ANOVA was used for statistical analysis. Scale bar represents $200 \mu \mathrm{m}$, original magnification, x200. (B) Pristimerin inhibited the Transwell migration ability of UM cells. Left, representative image of migration assay of 92.1 and Omm 1 cells after exposed to vehicle, 0.25 or $0.5 \mu \mathrm{M}$ pristimerin for $24 \mathrm{~h}$. Right, quantitative analysis of the migration cells was showed. Values were expressed as mean cell numbers in three random fields of view (x200) in three independent experiments. Error bars represented the means $\pm \mathrm{SE}$. ${ }^{*} \mathrm{P}<0.05,{ }^{* *} \mathrm{P}<0.01,{ }^{* * *} \mathrm{P}<0.001$, one-way ANOVA was used for statistical analysis. (C) Pristimerin suppressed the invasion ability of UM cells. The representative images of invaded cells which were treated with vehicle, 0.25 or $0.5 \mu \mathrm{M}$ pristimerin for $24 \mathrm{~h}$. Scale bar represents $200 \mu \mathrm{m}$ (left), and results of the invaded cells of per field (three random field) (right). The results showed as the means $\pm \mathrm{SE}$. ${ }^{* *} \mathrm{P}<0.01,{ }^{* * * *} \mathrm{P}<0.001$, one-way ANOVA was used for statistical analysis. (D) Pristimerin reduced the expression of MMP2 and MMP9 in a dose-dependent manner. The whole lysates of cells were used to detect the protein level of MMP2 and MMP9 by western blot analysis after Omm 1 and 92.1 cells were treated with pristimerin for $24 \mathrm{~h}$. (E) Pristimerin inhibited the activity of MMP9 in a dose-dependent manner. Omm 1 and 92.1 cells were cultured and treated with or without pristimerin $(0.25$ and $0.5 \mu \mathrm{M})$ for $24 \mathrm{~h}$. The serum-free medium of cells was used to detect the activity of MMP9 by gelatin zymography assay. The serum-free medium of MDA-MB-231 cells and serum-free medium without cells were used as positive control and negative control, respectively. The images (left) were the representative result, while the graphs (right) were the quantitative analysis of MMP9 activity at different concentration of pristimerin (n=3). The results showed as the means $\pm \mathrm{SE}$. ${ }^{*} \mathrm{P}<0.05,{ }^{* * *} \mathrm{P}<0.01$, one-way ANOVA was used for statistical analysis. 
A
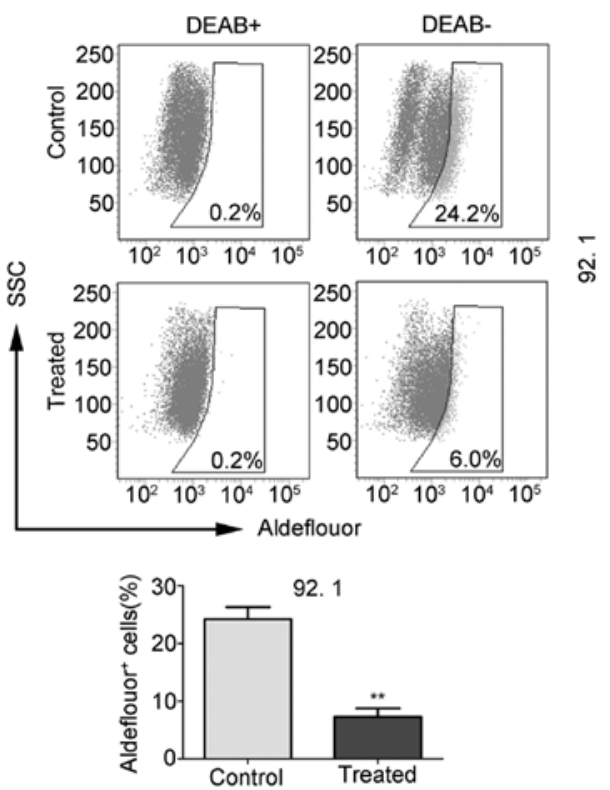

B
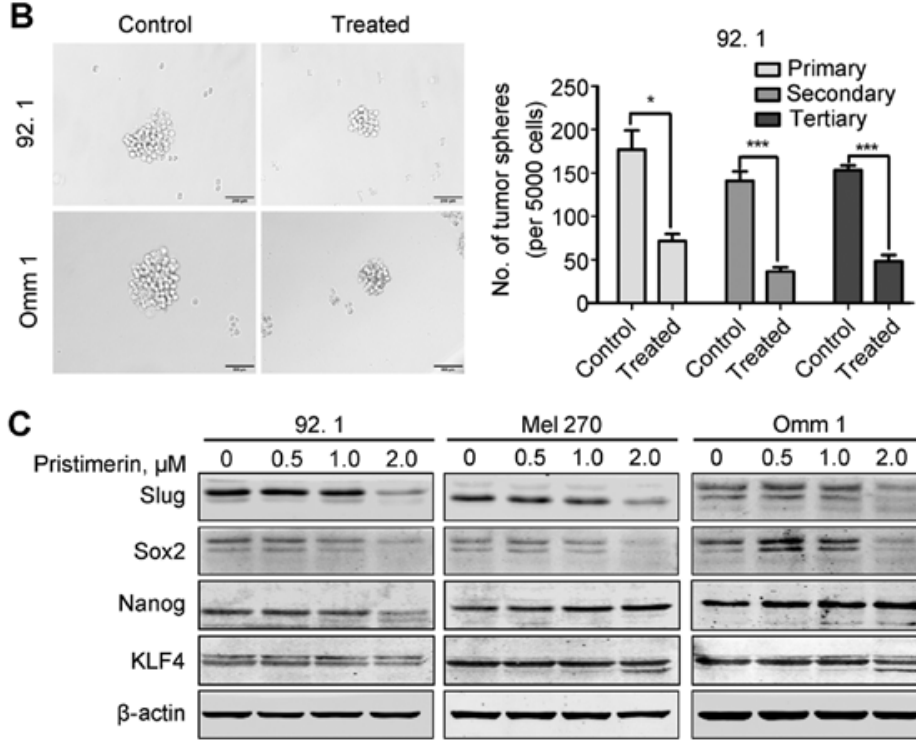
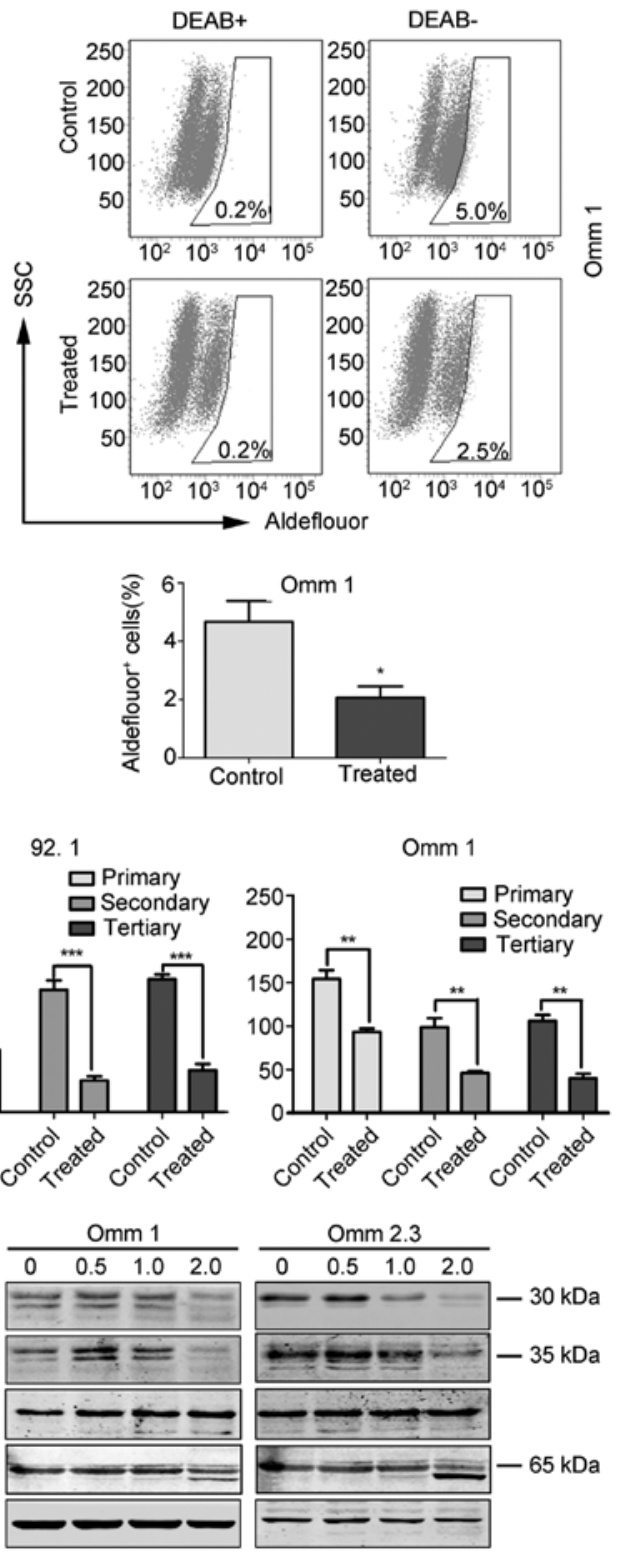

Figure 6. Pristimerin eradicates cancer stem-like cells in UM cells. (A) Pristimerin decreased the percentage of ALDH ${ }^{+}$cells in UM cells. 92.1 and Omm 1 cells were treated with DMSO-containing medium (control) or $1.0 \mu \mathrm{M}$ pristimerin (treated) for $24 \mathrm{~h}$, the percentage of $\mathrm{ALDH}^{+}$cells was measured by flow cytometry. Representative histograms are shown (top), and the graphs are quantitative analysis of ALDH ${ }^{+}$cell proportion (bottom). The results showed as the means \pm SE. ${ }^{*} \mathrm{P}<0.05,{ }^{* *} \mathrm{P}<0.01$, two-tailed Student's t-test. (B) Pristimerin exerted an inhibitory effect on the formation of melanospheres. 92.1 and Omm 1 cells were exposed to DMSO-containing DMEM/F12 medium (control) or $1.0 \mu \mathrm{M}$ pristimerin (treated) for $24 \mathrm{~h}$. Melanospheres ( $>50$ cells) were counted after two weeks. Right, three rounds of re-plating experiment results presented as the means $\pm \mathrm{SE}$. * $\mathrm{P}<0.05$, ${ }^{* *} \mathrm{P}<0.01$, two-tailed Student's t-test. Scale bar represents $200 \mu \mathrm{m}$. (C) Pristimerin downregulated the expression of stemness-indicative proteins of CSCs. UM cells were treated with different concentration pristimerin for $24 \mathrm{~h}$, and then subjected to western blotting.

and the anti-apoptotic role of survivin in pristimerin-inducing apoptosis in prostate cancer cells (38), we hypothesized that survivin might be critical in pristimerin-inducing apoptosis in UM cells. The Omm 1 cell ectopic overexpression of survivin by lentiviral construct encoding survivin were more resistant to pristimerin than cells transfected with empty vector (Fig. 4B). On the other hand, 92.1 cells were transfected with scramble or survivin shRNA, and the results showed that knockdown of survivin facilitated the sensitivity of UM cells to pristimerin (Fig. 4C). These data imply that survivin indeed plays a critical role in pristimerin-inducing apoptosis.

We next studied the regulation of survivin by pristimerin. qRT-PCR analysis showed that pristimerin treatment in 92.1 and Omm 1 cells led to a decrease in the mRNA level of BIRC5 (encoding survivin) (Fig. 4D). The results suggested that downregulation of survivin by pristimerin occurs at the level of transcription in UM cells.

Pristimerin inhibits migration and invasion of UM cells. Although multiple therapies are available for primary UM patients, therapeutic options are limited for the metastatic patients with no apparent reduced mortality in the past decades $(1,2,4)$. In order to investigate the effect of pristimerin on the motility of UM cells, wound healing ability was tested in 92.1 and Omm 1 cells. After $72 \mathrm{~h}$ of pristimerin treatment, the occlusion of UM cells was remarkably slowed (Fig. 5A). We next examined the 

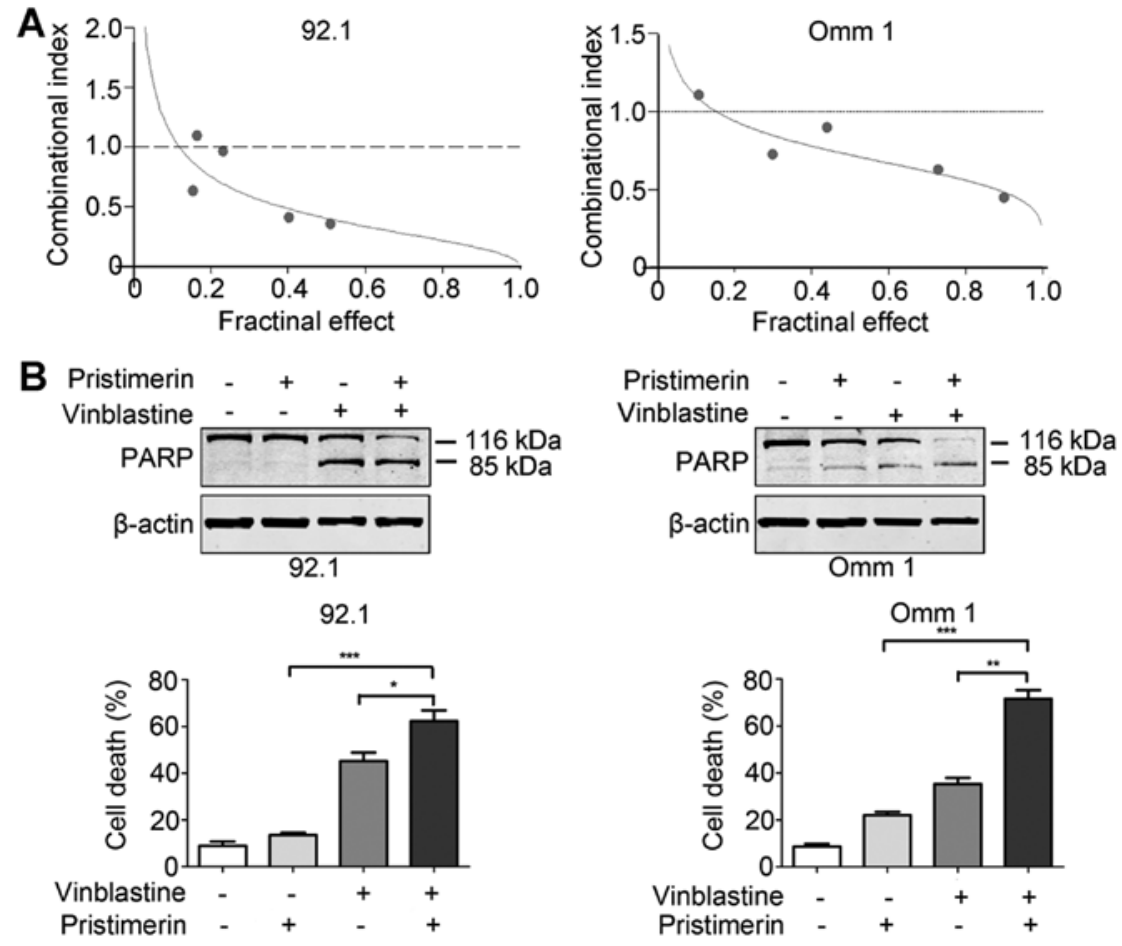

Figure 7. Pristimerin enhances the sensitivity of UM cells to vinblastine. (A) A synergistic effect of pristimerin and vinblastine was estimated by MTS assay after exposing 92.1 and Omm 1 cells with mixture of two drugs diluted in a serial and fixed ratio. (B) The enhanced apoptosis induced by pristimerin $(0.5 \mu \mathrm{M})$ and vinblastine $(200 \mathrm{nM})$ in UM cells was tested by western blotting (top) and trypan blue exclusion assay (bottom). ${ }^{*} \mathrm{P}<0.05,{ }^{* * *} \mathrm{P}<0.01,{ }^{* * * *} \mathrm{P}<0.001$, two-tailed Student's t-test.

inhibitory effect of pristimerin on Transwell migration and invasion and found that pristimerin profoundly decreased the number of migrated (Fig. 5B) and invaded (Fig. 5C) cells. Local invasion is an initial step of metastasis with involvement of matrix metalloproteinases (MMPs) $(29,39)$. We therefore assumed that pristimerin suppressed the invasion of UM cells by decreasing the expression or activity of MMP2 and MMP9. Western blotting results showed that pristimerin decreased the protein levels of MMP2 and MMP9 in a dose-dependent manner (Fig. 5D). Moreover, gelatin zymography assay results indicated that pristimerin inhibited the activity of MMP9 in a dose-dependent manner (Fig. 5E).

Pristimerin weakened the properties of cancer stem-like cells in UM cells. CSC theory holds a view that CSC is the main cause for metastasis and therapeutic resistant (40). Several in vitro assays such as $\mathrm{ALDH}^{+}$assay and tumor sphere formation allow for the study of CSCs (10). Flow cytometry analysis showed that the percentage of $\mathrm{ALDH}^{+}$ cells was significantly decreased in the cells treated with pristimerin compared to that in control group (Fig. 6A). On the other hand, three rounds of serially re-plating culture of melanoshpere showed that the numbers of melanosphere in the pristimerin-treated cells were significantly lower than those in control group (Fig. 6B), implying that pristimerin exerts an inhibitory activity on the self-renewal capacity of CSCs in UM cells. We also examined the universal stemness-related proteins which were also regulated by NF- $\kappa B$ pathway such as Slug, Sox2, Nanog and KLF4 (10), the results showed that the expression of Slug and Sox 2 was decreased in the cells treated with the highest concentration
$(2 \mu \mathrm{M})$ of pristimerin (Fig. 6C). The protein levels of Nanog and KLF4 remained constant (Fig. 6C).

Pristimerin enhances the sensitivity of UM cells to vinblastine. Vinblastine, a conventional chemotherapeutic agent, was used in clinical treatment of UM patients (3). We thus exploited whether pristimerin increased sensitivity of UM cells to vinblastine. The results of $72 \mathrm{~h}$ of combinational treatment showed a synergistic effect in 92.1 and Omm 1 cells (combinational index, $\mathrm{CI}<1$ ) (Fig. 7A). Furthermore, detection of PARP cleavage and trypan blue exclusion assay confirmed an enhanced apoptosis-inducing effect in UM cells (Fig. 7B).

\section{Discussion}

Although recent technical advances have opened up many new ways in treating primary UM patients, there are no effective therapeutic approaches for those who have metastasized. In this study, our results demonstrated that pristimerin displayed significant anticancer activities by blocking the NF- $\kappa \mathrm{B}$ pathway in UM cells. Pristimerin suppressed $\mathrm{TNF} \alpha$-induced I $\mathrm{BB} \alpha$ phosphorylation and degradation, translocation of $\mathrm{p} 65$, and expression of NF- $\mathrm{kB}$-dependent genes. Pristimerin effectively inhibited the malignant phenotypes such as proliferation, resistance to apoptosis, migration, invasion and CSCs in UM cells. Additionally, pristimerin decreased the expression of survivin at transcriptional level which plays a critical role in pristimerin-inducing apoptosis of UM cells.

It is well-known that cancer-related inflammation is a hallmaker of cancer (41). In physiologic condition, eyes are 
in a state of immune privilege without existences of immune cells. Once tumor occurs in the eyes, this state is challenged with infiltration with myeloid and T cells which constitute an intraocular inflammatory microenvironment (42). Previous evidence has demonstrated that cytokines and chemokines (e.g., TNF $\alpha$, IL-6, IL-8, IP-10, MIP-1 and IFN- $\gamma$ ) in the vitreous fluid of eyes with UM are elevated (43). Among them, $\mathrm{TNF} \alpha$ can activate the NF- $\kappa \mathrm{B}$ pathway (37). Moreover, hyperactivation of $\mathrm{NF}-\kappa \mathrm{B}$ not only contributes to aberrant local tumor cell survival and growth, but also promotes distant metastasis $(12,41,43)$. Thus, $\mathrm{NF}-\kappa \mathrm{B}$ inhibition appears to offer a promising strategy in cancer therapy in UM.

The CSC theory has emerged as an important landmark in the understanding of drug resistance and cancer recurrence, and CSCs are regarded as an essential cause of tumor metastasis, recurrence and drug tolerance (40). So far, many classic signal pathways such as Wnt/ $\beta$-catenin, Hedgehog, and Notch pathway have shown extensive involvement in the coordination of CSCs (40). Additionally, accumulating evidence indicated the existence of links between CSCs and NF- $\mathrm{NB}$ pathway (10). Our study showed that pristimerin inhibited the characteristic of CSCs in UM cells, which is consistent with a recent report in prostate cancer cells $(20,22)$. Given the fundamental role of Slug in CSCs in breast cancer (44), the role of Slug in UM CSCs need to be defined in the future.

In order to acquire better therapeutic outcomes, concomitant drugs become a conventional approach in clinical cancer therapy. Therefore, we chose vinblastine as a representative front line agent in our research to explore the potential value of pristimerin in UM clinical combination treatment. This is the first report that pristimerin has synergistic effect with vinblastine in UM cells.

Pristimerin is a compound isolated from nature products and the antitumor activity of this compound is complicated. It is reported that pristimerin modulates other molecular targets such as cyclins, apoptosis-related proteins, proteasome activity, AKT/mTOR and MAPK/ERK pathways contributing to its antitumor activity (14).

Our results indicated that pristimerin effectively blocks the $\mathrm{NF}-\kappa \mathrm{B}$ pathway, which contributes to the inhibition of malignant phenotypes in UM cells. However, we could not exclude the possibility of this compound to target other molecular pathways in UM cells.

In conclusion, pristimerin not only killed the bulk of tumor cells, but also effectively eliminated CSCs in UM cells. Pristimerin as a lead compound also exerted favorable anticancer effects both in single administration and combination with vinblastine. Thus, further clinical trial of pristimerin against UM may be warranted.

\section{Acknowledgements}

This study was supported by grants from National Natural Science Funds (nos. U1301226, and 81373434 to J. Pan), the National Basic Research Program of China (973 program no. 2009CB825506 to J. Pan), the Research Foundation of Education Bureau of Guangdong Province, China (no. cxzd1103 to J. Pan), and Natural Science Foundation of Guangdong province (no. 2015A030312014 to J. Pan).

\section{References}

1. Singh AD, Bergman L and Seregard S: Uveal melanoma: Epidemiologic aspects. Ophthalmol Clin North Am 18: 75-84, viii, 2005

2. Singh AD, Turell ME and Topham AK: Uveal melanoma: Trends in incidence, treatment, and survival. Ophthalmology 118: 1881-1885, 2011

3. Bedikian AY, Johnson MM, Warneke CL, Papadopoulos NE, Kim KB, Hwu WJ, McIntyre S, Rohlfs M, Homsi J and Hwu P: Does complete response to systemic therapy in patients with stage IV melanoma translate into long-term survival? Melanoma Res 21: 84-90, 2011.

4. Damato B and Heimann H: Personalized treatment of uveal melanoma. Eye (Lond) 27: 172-179, 2013.

5. Li B, Li YY, Tsao SW and Cheung AL: Targeting NF- $\kappa$ B signaling pathway suppresses tumor growth, angiogenesis, and metastasis of human esophageal cancer. Mol Cancer Ther 8: 2635-2644, 2009.

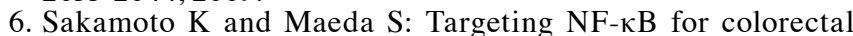
cancer. Expert Opin Ther Targets 14: 593-601, 2010.

7. Luedde $T$ and Schwabe RF: NF- $\kappa B$ in the liver - linking injury, fibrosis and hepatocellular carcinoma. Nat Rev Gastroenterol Hepatol 8: 108-118, 2011.

8. Nogueira L, Ruiz-Ontañon P, Vazquez-Barquero A, Moris F and Fernandez-Luna JL: The NF- $\kappa$ B pathway: A therapeutic target in glioblastoma. Oncotarget 2: 646-653, 2011.

9. Lu Z, Jin Y, Chen C, Li J, Cao Q and Pan J: Pristimerin induces apoptosis in imatinib-resistant chronic myelogenous leukemia cells harboring T315I mutation by blocking NF- $\kappa$ B signaling and depleting Bcr-Abl. Mol Cancer 9: 112, 2010.

10. Rinkenbaugh AL and Baldwin AS: The NF- $\kappa \mathrm{B}$ pathway and cancer stem cells. Cells 5: 5, 2016.

11. Lee CH, Jeon YT, Kim SH and Song YS: NF-кB as a potential molecular target for cancer therapy. Biofactors 29: 19-35, 2007.

12. Dror R,Lederman M, Umezawa K, Barak V,Pe'er J and Chowers I: Characterizing the involvement of the nuclear factor- $\kappa \mathrm{B}(\mathrm{NF} \kappa \mathrm{B})$ transcription factor in uveal melanoma. Invest Ophthalmol Vis Sci 51: 1811-1816, 2010.

13. Dirsch VM, Kiemer AK, Wagner H and Vollmar AM: The triterpenoid quinonemethide pristimerin inhibits induction of inducible nitric oxide synthase in murine macrophages. Eur J Pharmacol 336: 211-217, 1997.

14. Yousef BA, Hassan HM, Zhang LY and Jiang ZZ: Anticancer potential and molecular targets of pristimerin: A mini-review. Curr Cancer Drug Targets 17: 100-108, 2017.

15. Lee SO, Kim JS, Lee MS and Lee HJ: Anti-cancer effect of pristimerin by inhibition of HIF-1 $\alpha$ involves the SPHK-1 pathway in hypoxic prostate cancer cells. BMC Cancer 16: 701, 2016.

16. Xie G, Yu X, Liang H, Chen J, Tang X, Wu S and Liao C: Pristimerin overcomes adriamycin resistance in breast cancer cells through suppressing Akt signaling. Oncol Lett 11: 3111-3116, 2016.

17. Yousef BA, Hassan HM, Guerram M, Hamdi AM, Wang B, Zhang LY and Jiang ZZ: Pristimerin inhibits proliferation, migration and invasion, and induces apoptosis in HCT-116 colorectal cancer cells. Biomed Pharmacother 79: 112-119, 2016.

18. Zhao H, Wang C, Lu B, Zhou Z, Jin Y, Wang Z, Zheng L, Liu K, Luo T, Zhu D, et al: Pristimerin triggers AIF-dependent programmed necrosis in glioma cells via activation of JNK. Cancer Lett 374: 136-148, 2016.

19. Deng Q, Bai S, Gao W and Tong L: Pristimerin inhibits angiogenesis in adjuvant-induced arthritic rats by suppressing VEGFR2 signaling pathways. Int Immunopharmacol 29: 302-313, 2015.

20. Huang S, He P, Peng X, Li J, Xu D and Tang Y: Pristimerin inhibits prostate cancer bone metastasis by targeting PC-3 stem cell characteristics and VEGF-induced vasculogenesis of BM-EPCs. Cell Physiol Biochem 37: 253-268, 2015.

21. Yousef BA, Guerram M, Hassan HM, Hamdi AM, Zhang LY and Jiang ZZ: Pristimerin demonstrates anticancer potential in colorectal cancer cells by inducing G1 phase arrest and apoptosis and suppressing various pro-survival signaling proteins. Oncol Rep 35: 1091-1100, 2016.

22. Zuo J, Guo Y, Peng X, Tang Y, Zhang X, He P, Li S, Wa Q, Li J, Huang S, et al: Inhibitory action of pristimerin on hypoxia-mediated metastasis involves stem cell characteristics and EMT in PC-3 prostate cancer cells. Oncol Rep 33: 1388-1394, 2015.

23. Ma YW, Liu YZ and Pan JX: Verteporfin induces apoptosis and eliminates cancer stem-like cells in uveal melanoma in the absence of light activation. Am J Cancer Res 6: 2816-2830, 2016. 
24. Jin B, Ding K and Pan J: Ponatinib induces apoptosis in imatinibresistant human mast cells by dephosphorylating mutant D816V KIT and silencing $\beta$-catenin signaling. Mol Cancer Ther 13: 1217-1230, 2014.

25. Jin Y, Lu Z, Ding K, Li J, Du X, Chen C, Sun X, Wu Y, Zhou J and Pan J: Antineoplastic mechanisms of niclosamide in acute myelogenous leukemia stem cells: Inactivation of the NF- $\kappa B$ pathway and generation of reactive oxygen species. Cancer Res 70: 2516-2527, 2010

26. Jin Y, Zhou J, Xu F, Jin B, Cui L, Wang Y, Du X, Li J, Li P, Ren R, et al: Targeting methyltransferase PRMT5 eliminates leukemia stem cells in chronic myelogenous leukemia. J Clin Invest 126: 3961-3980, 2016.

27. Pan J, Quintás-Cardama A, Kantarjian HM, Akin C, Manshouri T, Lamb P, Cortes JE, Tefferi A, Giles FJ and Verstovsek S: EXEL-0862, a novel tyrosine kinase inhibitor, induces apoptosis in vitro and ex vivo in human mast cells expressing the KIT D816V mutation. Blood 109: 315-322, 2007.

28. Jin B, Wang C, Li J, Du X, Ding K and Pan J: Anthelmintic niclosamide disrupts the interplay of $\mathrm{p} 65$ and FOXM1/ $\beta$-catenin and eradicates leukemia stem cells in chronic myelogenous leukemia. Clin Cancer Res 23: 789-803, 2017.

29. Dai W, Zhou J, Jin B and Pan J: Class III-specific HDAC inhibitor Tenovin-6 induces apoptosis, suppresses migration and eliminates cancer stem cells in uveal melanoma. Sci Rep 6: 22622 , 2016.

30. Morrison DJ, Hogan LE, Condos G, Bhatla T, Germino N, MoskowitzNP,Lee L, Bhojwani D, Horton TM,Belitskaya-Levy I, et al: Endogenous knockdown of survivin improves chemotherapeutic response in ALL models. Leukemia 26: 271-279, 2012.

31. Livak KJ and Schmittgen TD: Analysis of relative gene expression data using real-time quantitative PCR and the 2(-Delta Delta C(T)) method. Methods 25: 402-408, 2001.

32. Yarrow JC, Perlman ZE, Westwood NJ and Mitchison TJ: A high-throughput cell migration assay using scratch wound healing, a comparison of image-based readout methods. BMC Biotechnol 4: 21, 2004.

33. Dinicola S, Pasqualato A, Cucina A, Coluccia P, Ferranti F, Canipari R, Catizone A, Proietti S, D'Anselmi F, Ricci G, et al Grape seed extract suppresses MDA-MB231 breast cancer cell migration and invasion. Eur J Nutr 53: 421-431, 2014.
34. Toth M and Fridman R: Assessment of gelatinases (MMP-2 and MMP-9 by gelatin zymography. Methods Mol Med 57: 163-174, 2001.

35. Ginestier C, Hur MH, Charafe-Jauffret E, Monville F, Dutcher J, Brown M, Jacquemier J, Viens P, Kleer CG, Liu S, et al: ALDH1 is a marker of normal and malignant human mammary stem cells and a predictor of poor clinical outcome. Cell Stem Cell 1: 555-567, 2007.

36. Nonaka M, Yawata T, Takemura M, Higashi Y, Nakai E, Shimizu K and Ueba T: Elevated cell invasion in a tumor sphere culture of RSV-M mouse glioma cells. Neurol Med Chir (Tokyo) 55: 60-70, 2015.

37. Chen LF and Greene WC: Shaping the nuclear action of NF-кB. Nat Rev Mol Cell Biol 5: 392-401, 2004.

38. Liu YB, Gao X, Deeb D, Brigolin C, Zhang Y, Shaw J, Pindolia K and Gautam SC: Ubiquitin-proteasomal degradation of antiapoptotic survivin facilitates induction of apoptosis in prostate cancer cells by pristimerin. Int J Oncol 45: 1735-1741, 2014.

39. Huang Q, Lan F, Wang X, Yu Y, Ouyang X, Zheng F, Han J, Lin Y, Xie Y, Xie F, et al: IL-1 $\beta$-induced activation of p38 promotes metastasis in gastric adenocarcinoma via upregulation of AP-1/c-fos, MMP2 and MMP9. Mol Cancer 13: 18, 2014.

40. Clarke MF, Dick JE, Dirks PB, Eaves CJ, Jamieson CH, Jones DL, Visvader J, Weissman IL and Wahl GM: Cancer stem cells-perspectives on current status and future directions: AACR Workshop on cancer stem cells. Cancer Res 66: 9339-9344, 2006.

41. Hanahan D and Weinberg RA: Hallmarks of cancer: The next generation. Cell 144: 646-674, 2011.

42. Bronkhorst IH and Jager MJ: Inflammation in uveal melanoma. Eye (Lond) 27: 217-223, 2013.

43. Nagarkatti-Gude N, Bronkhorst IH, van Duinen SG, Luyten GP and Jager MJ: Cytokines and chemokines in the vitreous fluid of eyes with uveal melanoma. Invest Ophthalmol Vis Sci 53: 6748-6755, 2012.

44. Storci G, Sansone P, Mari S, D'Uva G, Tavolari S, Guarnieri T, Taffurelli M, Ceccarelli C, Santini D, Chieco P, et al: TNFalpha up-regulates SLUG via the NF-kappaB/HIF1alpha axis, which imparts breast cancer cells with a stem cell-like phenotype. J Cell Physiol 225: 682-691, 2010. 